\title{
FRACTAL FEATURES OF SOIL PARTICLES UNDER DIFFERENT PLANT COMMUNITIES IN THE YIMENG MOUNTAIN OF CHINA
}

\author{
LI, H. ${ }^{1}-$ ZHAN, H. X. ${ }^{2}-\mathrm{XU}, \mathrm{H} .^{*}$ \\ ${ }^{I}$ Department of Landscape Architecture, School of Geography, Geomatics and Planning, \\ Jiangsu Normal University, Xuzhou 221116, China \\ ${ }^{2}$ Forestry College, Shandong Agricultural University, Tai'an 271018, China \\ *Corresponding author \\ e-mail:yiduohuanle@163.com
}

(Received $8^{\text {th }}$ Sep 2019; accepted $15^{\text {th }}$ Nov 2019)

\begin{abstract}
The vegetation in fragile ecological areas easily degrades and the original ecosystem is hard to preserve. This paper attempts to disclose the effects of different plant communities on the physical properties of the soil in the Yimeng Mountains of eastern China. For this purpose, the relative weight of soil particles in varied sizes was measured by the mechanical sieving method firstly. Next, the fractal dimensions of soil particles were computed based on their mass. After that, the uniformity and curvature were calculated for soil particles in varied sizes, under the cumulative percentage contents of $10 \%, 30 \%$, and $60 \%$. The results show that the local soil is predominately coarse sandy soil and the soil structure of forests is way better than that of slope wasteland; by fractal dimension, the coverage types were ranked in descending order as mixed forest > pure forest > economic forest > farmland > slope wasteland; the fractal dimension has a significant positive correlation with the particle size of fine sandy soil and coarse powder. The research findings shed new light on how to select tree species and design vegetation types to recover and reconstruct the vegetation in mountainous regions of eastern China.
\end{abstract}

Keywords: fractal dimension, soil structure, uniformity, plant diversity, ecological protection

\section{Introduction}

More than $60 \%$ of China is covered by fragile ecological areas, where vegetation easily degrades and the ecology is hard to preserve. The vegetation growth largely depends on the soil properties. In return, the soil properties are directly and indirectly affected by the overlying vegetation. The plant communities provide above- and belowground litterfall, release and recycle nutrients, modify the microclimate, regulate the water cycle, and alter the composition of fauna and flora in soil (Jose, 2009; Li et al., 2016). However, the soil structure is extremely complex. Some soil properties are too irregular and stochastic to describe by traditional statistical methods (Turcotte, 1986; Xiao et al., 2014; Luo et al., 2015).

The above problem can be solved effectively by fractal theory, powerful tool to tackle complex phenomena. The fractal theory has been widely adopted in numerous fields ( $\mathrm{Li}$ and Wei, 2014). Since the 1980s, fractal theory has been applied to soil science (Turcotte, 1986; Gao et al., 2014; Sun et al., 2019). In the following decade, many scholars explored the feasibility of characterizing particle size distribution with fractal theory (Tyler and Wheatcraft, 1992; Su et al., 2004; Wei et al., 2016). The particle size distribution is an important physical attribute of soil that changes with the soil conditions (Xu et al., 2013; Lyu et al., 2015). The variation of the soil particle size distribution helps to identify the structure, dynamics and physical processes of soil (Ghorbani et al., 2012; Peng et al., 2014). 
The fractal dimension is a useful metric to quantify various soil properties, namely, structure, erodibility (Perfect, 1997; Xia et al., 2015; Deng et al., 2018) and water permeability (Yu et al., 2015; Zhao et al., 2016; Zhao et al., 2017). The fractal information facilitates the design of soil conservation measures and selection of vegetation types in plateaus and mountainous regions (Liu et al., 2009; Wei et al., 2016). However, the fractal theory has not been extensively applied to analyze the soil particle size distribution in the Yimeng Mountain of central Shandong, China. In addition, the impacts of plant communities on the composition and distribution of soil particles remain unclear.

To make up for the gaps, this paper analyses the fractal features of soil particles under 11 plant communities in the Yimeng Mountains of eastern China. The analysis results shed new light on how to select tree species and design vegetation types to recover and reconstruct the vegetation in mountainous regions of eastern China, laying the technical basis for erosion control in fragile ecological areas.

The remainder of this paper is organized as follows: Section 2 describes the test materials and methods; Section 3 analyzes the composition, fractal dimension and size distribution of soil particles under 11 plant communities, and discusses the impacts of fractal dimension on the composition and uniformity of soil particles; Section 4 puts forward the research conclusions. This study attempts to disclose the effects of different plant communities on the physical properties of the soil in the Yimeng Mountains of eastern China. For this purpose, 11 local plant communities were selected, and the fractal theory was employed to examine their effects on the composition and size distribution of soil particles.

\section{Materials and Methods}

\section{Study area}

As shown in Figure 1, the study area lies in the upstream of the Taihe Reservoir, a large water conservancy project on the Zihe River. Located in the southeast of Zichuan District, Zibo Prefecture, Shandong Province, the northern part of the Yimeng Mountain of eastern China $\left(117.9^{\circ} \mathrm{E}-118.2^{\circ} \mathrm{E}, 36.3^{\circ} \mathrm{N}-36.7^{\circ} \mathrm{N}\right)$, this area spans across several counties and towns, covering a total area of $278.02 \mathrm{~km}^{2}$.

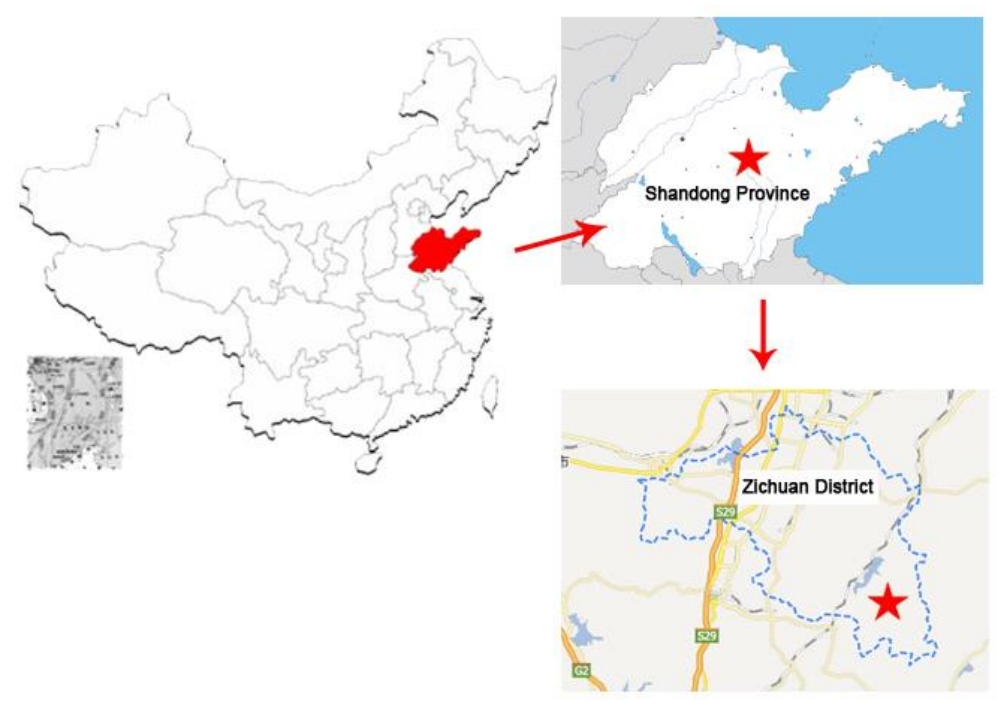

Figure 1. Location and satellite map of the study area 
The maximum south-to-north distance is $18.2 \mathrm{~km}$ and the maximum east-to-west distance is $26 \mathrm{~km}$. The region is a warm-temperature and semi-arid continental monsoon climate, with annual average temperature of $12.9^{\circ} \mathrm{C}$. Annual average precipitation is 664 mm with 70\% occurring between June and August. Annual average sunshine time is 2364 $\mathrm{h}$, and the frostfree period is 189 days.

The soil type in the project area is mainly brown soil, and there are three subclasses: the brown soil subclasses, the leaching brown soil subclasses and the brown soil subclasses. The vegetation type has three types of natural vegetation, artificial vegetation and cultivated crops, among which, the natural vegetation is mainly grass and wild shrubs, and the natural vegetation is mainly of grass and wild shrubs, and the main tree species of the artificial vegetation are pinus thunbergii, pinus densifla, Quercus acutissima, Robinia pseudoacaca and Castanea mollissima, etc. The cultivated crops are sweet potato, scutellaria baicalensis, and the rest are wheat, corn and soybean. Typical plant communities and soil types in the Yimeng Mountain can be found in the study area (Figure 2).

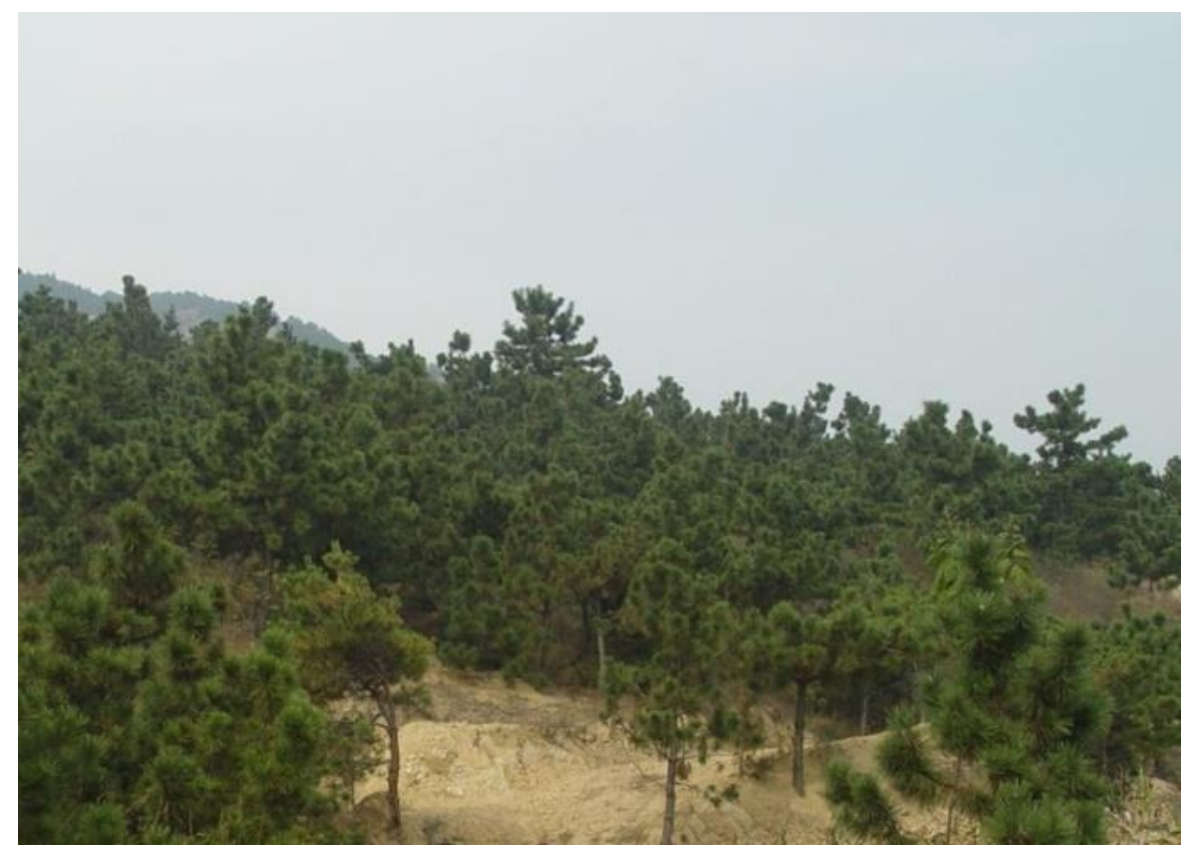

Figure 2. Photos of the study area

\section{Test materials}

As shown in Table 1, eleven typical plant communities were selected from the study area to identify the size distribution of soil particles, and disclose the effects of vegetation types on the fractal dimension of soil particles (Figure 3). The eleven plant communities belong to five vegetation types, namely, pure forest (Pinus thunbergii and Robinia pseudoacacia), mixed forest (Robinia pseudoacacia- Quercus acutissima and Pinus densiflora- Pinus thunbergii), economic forest (Castanea mollissima and apple), farmland (Scutellaria baicalensis, sweet potato, other crops) and slope wasteland (wild grass 1 and wild grass 2). Three test plots were set up in each land use type, and the test sample points were determined according to the diagonal 3-point sampling method in each sample plot, repeat three samples (average analysis) at each test sample point. 
Table 1. Selected vegetation types and plant communities

\begin{tabular}{c|c|c|c|c}
\hline Vegetation types & Plant communities & Abbreviations & $\begin{array}{c}\text { Serial } \\
\text { number }\end{array}$ & GPS coordinates \\
\hline \multirow{2}{*}{ Pure forest } & Pinus thunbergii & PT & 1 & $118.17 \mathrm{E}, 36.46 \mathrm{~N}$ \\
& Robinia pseudoacacia & RP & 2 & $118.19 \mathrm{E}, 36.47 \mathrm{~N}$ \\
Mixed forest & Robinia pseudoacacia- Quercus acutissima & RQ & 3 & $118.20 \mathrm{E}, 36.50 \mathrm{~N}$ \\
& Pinus densiflora- Pinus thunbergii & PP & 4 & $118.14 \mathrm{E}, 36.48 \mathrm{~N}$ \\
Economic forest & Castanea mollissima & CM & 5 & $118.17 \mathrm{E}, 36.48 \mathrm{~N}$ \\
& Apple & A & 6 & $118.16 \mathrm{E}, 36.50 \mathrm{~N}$ \\
Farmland & Scutellaria baicalensis & OC & 7 & $118.12 \mathrm{E}, 36.44 \mathrm{~N}$ \\
& Other crops & SP & 9 & $118.11 \mathrm{E}, 36.46 \mathrm{~N}$ \\
Slope wasteland & Sweet potato & WG1 & 10 & $118.17 \mathrm{E}, 36.53 \mathrm{~N}$ \\
& Wild grass 1 & WG2 & 11 & $118.18 \mathrm{E}, 36.54 \mathrm{~N}$ \\
& Wild grass 2 & & &
\end{tabular}

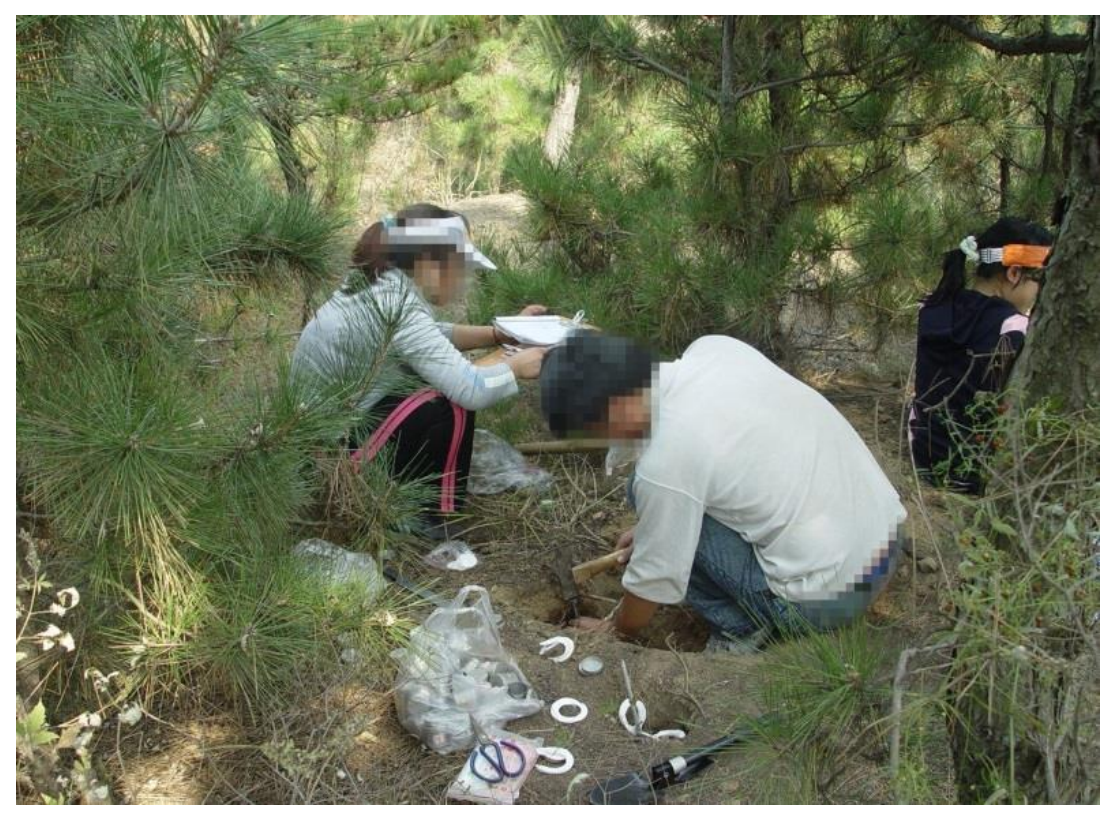

Figure 3. Photos of the sampling site

\section{Test methods}

\section{Composition of soil particles}

The size and weight distributions of soil particles were tested by the mechanical sieving method (dry sieving). Firstly, soil samples (particle size: $0 \sim 40 \mathrm{~cm}$ ) of each plant community from five points, dried and then mixed. The gravels with diameter greater than $2 \mathrm{~mm}$ were filtered out. Next, the relative weight contents of soil particles in varied sizes were measured by a ZBSX-92A standard electric sieve shaker (sieve swaying times: 221 times/min; shaking times: 147 times/min; shaking amplitude: $25 \mathrm{~mm}$; motor power: $0.37 \mathrm{~kW}$ ) with sieve sizes of $1.00,0.50,0.25,0.10$ and $0.05 \mathrm{~mm}$.

\section{Fractal dimension of soil particles}

After the soil samples were dry-sieved, the weights and percentage contents of soil particles in varied sizes were measured and calculated. On this basis, the fractal dimensions of soil particles were computed based on their mass weight, assuming that 
soil particles in varied sizes have the same density. The quantitative distribution of soil particles was represented by weight distribution (Yang et al., 1993). Then, the fractal dimension (D) can be derived by the method of limits.

$$
\mathrm{D}=3-\lg \left(\frac{w_{i}}{w_{o}}\right) / \lg \left(\frac{d_{i}^{*}}{d_{\text {max }}^{*}}\right)
$$

where $w_{\mathrm{i}}$ is the cumulative mass of soil particles smaller than $d_{\mathrm{i}}^{*} ; w_{0}$ is the total weight of all soil particles; $d_{\mathrm{i}}^{*}$ is the mean particle diameter $(\mathrm{mm})$ between $d_{\mathrm{i}}$ and $d_{\mathrm{i}+1}$ of two adjacent particle size; $d_{\max }{ }^{*}$ is the mean diameter of the largest soil particle. The mean particle diameter is the arithmetic mean of the upper and lower sieve sizes.

\section{Size distribution of soil particles}

Based on the weights of soil particles in varied sizes, the size distribution of soil particles was described by the tabular method and the cumulative curve method. The particle sizes corresponding to the cumulative percentage contents of $10 \%, 30 \%$ and $60 \%$ were denoted as $d_{10}, d_{30}$, and $d_{60}$, respectively. The index $d_{10}$ means the particles smaller than this size account for $10 \%$ of the total soil mass. The meanings of $d_{30}$ and $d_{60}$ can be derived by analogy. The size distribution was measured by two coefficients, namely, uniformity $\left(C_{\mathrm{u}}\right)$ and curvature $\left(C_{\mathrm{c}}\right)$ :

$$
\begin{gathered}
C_{\mathrm{u}}=d_{60} / d_{10} \\
C_{\mathrm{c}}=\mathrm{d}_{30}{ }^{2} /\left(d_{60} \times d_{10}\right)
\end{gathered}
$$

where $d_{10}$ is the effective particle size, i.e. the pore diameter of the sieve; $d_{60}$ is the control particle size. The uniformity is a key evaluation index of particle size distribution. A high uniformity means a wide distribution of particle sizes (If $C_{\mathrm{u}}<5$, the soil is uniform but poorly graded; if $C u>10$, the soil is well graded), but an excessively high uniformity may cause discontinuous grading, i.e. the absence of medium particle size. Thus, the curvature index was introduced to measure the overall shape of the cumulative curve.

\section{Results and Analysis}

\section{Composition of soil particles}

\section{Size distribution of soil particles}

Most soil particles were irregular, some varied greatly in three-dimensional (3D) size, and coarse and fine soil particles differed markedly in properties. For simplicity, the soil particles were viewed as smooth solid spheres, and divided into several groups based on diameter according to a standard for soil size fraction in China (Table 2) (Huang, 2000).

\section{Composition of soil particles}

The relative contents of dry-sieved soil particles in varied sizes are displayed in Table 3 below. As shown in Tables 2 and 3, the soil particle sizes ranged between 0.25 and $1.0 \mathrm{~mm}$ under different plant communities, indicating that the local soil is predominately coarse sandy soil. This soil structure is a typical pattern in rocky hills of 
northern China. The lack of fine particles (e.g. powder and clay particles), coupled with the high content of sandy soil, makes the soil structure extremely weak, loose and permeable, which is unfavorable to soil conservation (Deng et al., 2008).

By plant communities, the sampling sites of PT, RP and RQ were all rich in clay and powder particles; the sampling sites of A, WG1 and WG2 had high contents of fine sandy soils; the sampling sites of SP, SB and OC were dominated by sandy soils. The results show that both mixed and pure forests have a much better soil structure than slope wasteland, and mixed forest has more rational soil structure than pure forest. Therefore, needle-broad leaved or broad-leaved mixed forest can increase the contents of fine particles (e.g. clay and powder particles) in soil, and reduce the content of sandy soils. This is conducive to the soil structure and soil conservation. By contrast, the farmland witnesses a gradual reduction of fine sandy soils, which undermines the soil texture. This calls for prompt improvement of cultivation and irrigation methods.

Table 2. The standard for soil size fraction

\begin{tabular}{c|c|c}
\hline \multicolumn{2}{|c|}{ Name of particle } & Size $(\mathbf{m m})$ \\
\hline Gravel & Gravel & $2 \sim 1$ \\
\hline \multirow{3}{*}{ Sand } & Coarse sand & $1 \sim 0.5$ \\
& \multirow{2}{*}{ Fine sand } & $0.5 \sim 0.25$ \\
\cline { 2 - 3 } & & $0.25 \sim 0.2$ \\
& Coarse powder & $0.2 \sim 0.1$ \\
& Powder & $0.1 \sim 0.05$ \\
\hline
\end{tabular}

Table 3. Composition of soil particles under different plant communities

\begin{tabular}{c|ccccc|c}
\hline \multirow{2}{*}{ Plant communities } & \multicolumn{7}{|c}{ Percentage contents of soil particles in varied sizes (\%) } \\
\cline { 2 - 7 } & $\mathbf{1 ~ 2}$ & $\mathbf{0 . 5} \mathbf{1}$ & $\mathbf{0 . 2 5} \mathbf{0 . 5}$ & $\mathbf{0 . 1} \mathbf{0 . 2 5}$ & $\mathbf{0 . 0 5} \mathbf{0 . 1}$ & $\leq \mathbf{0 . 0 5}$ \\
\hline PT & 21.34 & 28.18 & 14.92 & 19.15 & 6.2 & 10.21 \\
RP & 16.51 & 24.05 & 15.48 & 22.02 & 7.45 & 14.48 \\
RQ & 22.73 & 27.34 & 13.08 & 16.68 & 6.59 & 13.59 \\
PP & 19.12 & 28.09 & 14.56 & 17.34 & 5.7 & 15.18 \\
CM & 21.57 & 32.54 & 16.87 & 17.94 & 4.49 & 6.59 \\
A & 18.65 & 27.04 & 14.89 & 20.98 & 7.32 & 11.12 \\
SB & 20.7 & 32.51 & 18.12 & 18.56 & 4.52 & 5.6 \\
OC & 17.5 & 40.2 & 22.55 & 14.05 & 2.19 & 3.51 \\
SP & 20.51 & 31.53 & 18.11 & 19.32 & 4.38 & 6.15 \\
WG1 & 25.88 & 34.19 & 14.92 & 16.71 & 3.42 & 2.99 \\
WG2 & 36.69 & 35.08 & 12.1 & 9.35 & 2.26 & 4.52 \\
\hline
\end{tabular}

* Abbreviations of plant communities please refer to table 1 in detail

\section{Fractal features of soil particles}

\section{Fractal dimension of soil particles under different plant communities}

The fractal dimensions of soil particles were calculated by linear regression with Equation 1. The results are recorded in Table 4. Based on the data in Table 4, a graph (Figure 4) was plotted with fractal dimension as the y-coordinate and plant community as the $\mathrm{x}$-coordinate.

As shown in Table 4, the calculated fractal dimensions fell within a small interval: 2.0044 2.4925. The results are basically within the range of sandy soil in China 
(1.834 2.641) (Hu et al., 2003). This conclusion agrees with the data in Table 3. It can be seen from Figure 4 that RQ corresponded to the highest fractal dimension, followed by PP, RP, A, PT, CM, SB, OC, WG2, WG1 and SP in succession.

Table 4. D-value of soil particles under different plant communities

\begin{tabular}{c|c|c|c|c}
\hline Types & Code & Sample plot & Slope & D \\
\hline \multirow{2}{*}{ Pure forest } & PT & 1 & 0.98 & 2.3574 \\
& RP & 2 & 0.97 & 2.4542 \\
\hline \multirow{2}{*}{ Mixed forest } & RQ & 3 & 0.99 & 2.4925 \\
& PP & 4 & 0.99 & 2.4618 \\
\hline \multirow{2}{*}{ Economic forest } & CM & 5 & 0.98 & 2.2908 \\
& A & 6 & 0.97 & 2.3845 \\
\hline \multirow{2}{*}{ Farmland } & SB & 7 & 0.97 & 2.2002 \\
& OC & 8 & 0.97 & 2.1798 \\
& SP & 9 & 0.97 & 2.0044 \\
\hline \multirow{2}{*}{ Slope wasteland } & WG1 & 10 & 0.99 & 2.1152 \\
& WG2 & 11 & 0.97 & 2.1367 \\
\hline
\end{tabular}

* Abbreviations of Code please refer to table 1 in detail

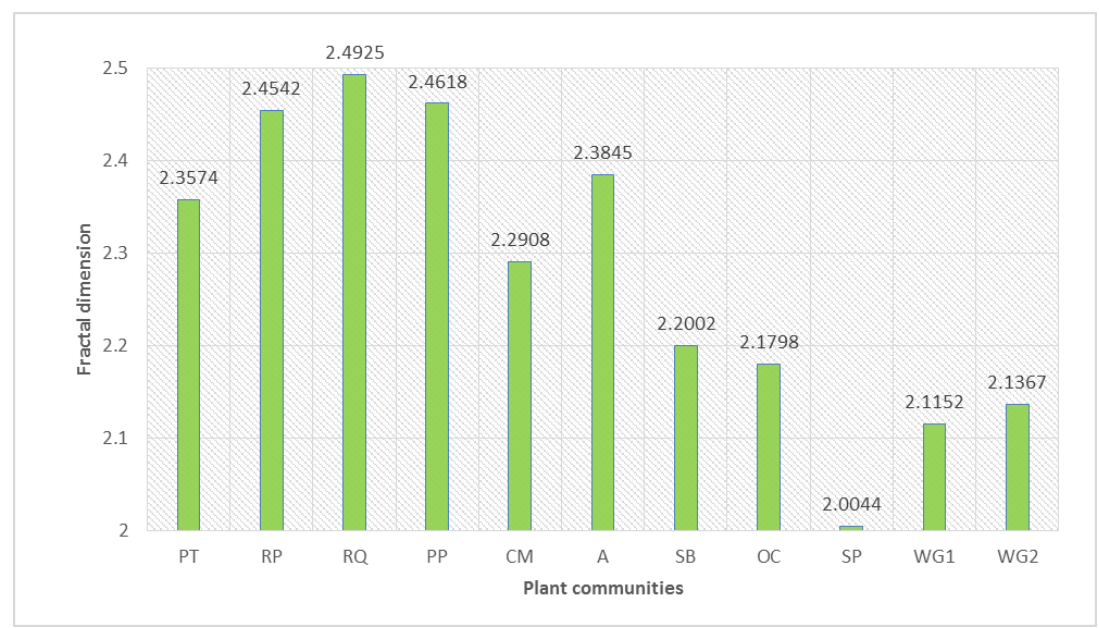

Figure 4. The fractal dimensions of soil particles under different plant communities

\section{Effects of coverage type on fractal dimension}

The effects of coverage type on fractal dimension are manifested as soil improvement and protection of plant communities. In Table 4 and Figure 4, the fractal dimensions of the 11 plant communities fell between 2.0044 and 2.4925. Thus, all types of plant communities have a major impact on fractal dimension.

By fractal dimension, the coverage types were ranked in descending order as mixed forest $>$ pure forest $>$ economic forest $>$ farmland $>$ slope wasteland.

The forests had higher dimensional values than the other vegetation types, revealing that forest species can greatly enhance soil structure. Among forest lands, mixed forest (RQ > PP) is the most effective vegetation type to ameliorate soil structure, followed by pure forest and economic forest. The advantage of forests is attributable to the importance of forest species in soil development. The soil beneath forests often features small particle 
size, good air permeability and coexistence of large and small pores. This type of soil is easy to conserve.

By contrast, farmland and slope wasteland showed similarly small fractal dimensions. This means the coarse soil texture under crops can slightly improve the soil structure. The soil texture is coarsen by the erosion of gravel surface.

\section{Relationship between content and fractal dimension}

Based on Tables 3 and 4, the relationship between content and fractal dimension of soil particle in each size was plotted (Figure 5). It can be seen that the percentage contents of soil particles in varied sizes differed in their impacts on fractal dimension. Overall, fractal dimension has a linear correlation with the content of soil particles in each size. The linear correlation was significantly positive for fine sandy soil and coarse powder, as evidenced by the correlation coefficients $\left(\mathrm{R}^{2}\right)$ : 0.2888 and 0.901 . By contrast, the linear correlation was significantly negative for coarse sandy soil, with the $\mathrm{R}^{2}$ being 0.7342 ; the linear correlation was not evident for gravel. The results show that the percentage contents of soil particles in varied sizes have different correlations with fractal dimension. This finding may be related to the high percentage contents of soil particles in other sizes within the study area. The fractal dimension failed to reflect the non-uniformity of soil texture in the study area correctly, implying that it cannot clearly measure the content variation of soil in each particle size.

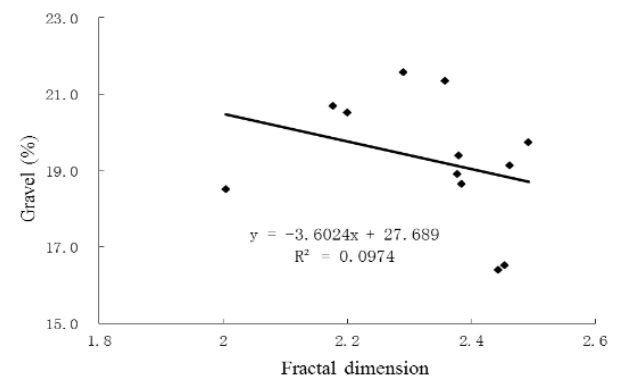

a. Gravel

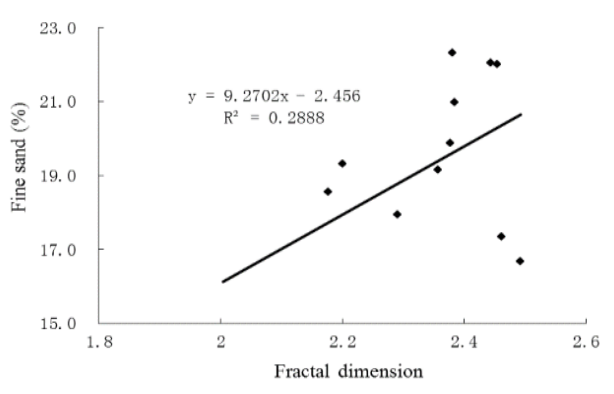

c. Fine sand

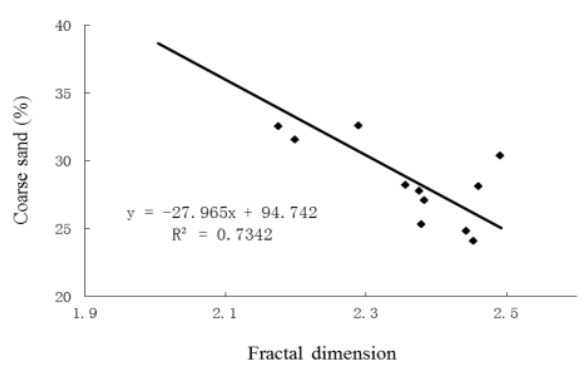

b. Coarse sand

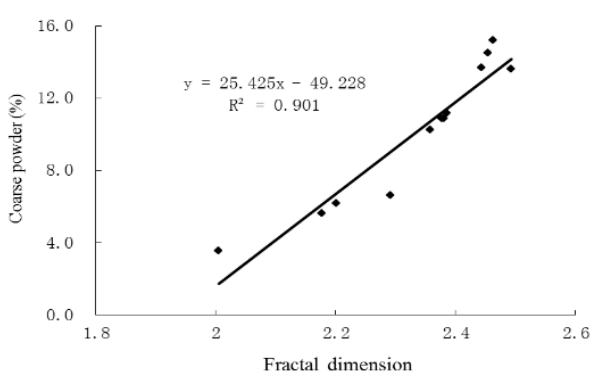

d. Coarse powder

Figure 5. The relationship between percentage content and fractal dimension of soil particle in each size

Combining with existing research results, the author found that fractal dimension is closely related to the size, quantity, and distribution uniformity of soil particles. The fractal dimension changed evidently with soil particle size. The above results show that the fractal dimension is an important index to evaluate soil texture. Small soil particles tend to have a high fractal dimension, because of their fine texture and high content of 
fine particles, while large soil particles usually have a low fractal dimension. In other word, the fractal dimension increases with the size of soil particles. The fractal dimension of sandy soil was significantly lower than that of loam and clay soils. High fractal dimensions mean good soil texture but poor air permeability, which contribute to soil conservation. The inverse is also true. Furthermore, since water and wind erosions mainly induce losses of superficial clay and powder particles, a low content of fine particles indicates serious soil erosion. Therefore, the prediction of fractal dimension is critical to the evaluation of the degree of soil erosion.

\section{Uniformity and curvature of soil under different vegetation types}

The uniformity and curvature of soil under each plant community were computed by Equations 2 and 3, respectively. The computed results (Table 5) show that PT led to the highest uniformity, followed in descending order by RQ, RP, PP, A, CM, SB, OC, SP, WG1 and WG2. By uniformity, the five vegetation types were ranked in ascending order as of slope wasteland $<$ farmland $<$ economic forest $<$ mixed forest $<$ pure forest.

Table 5. The uniformity and curvature of soil under each plant community

\begin{tabular}{c|c|c|c|c|c}
\hline Plant community & $\mathbf{d}_{\mathbf{6 0}}$ & $\mathbf{d}_{\mathbf{3 0}}$ & $\mathbf{d}_{\mathbf{1 0}}$ & $\mathbf{C}_{\mathbf{u}}$ & $\mathbf{C}_{\mathbf{c}}$ \\
\hline PT & 0.56 & 0.18 & 0.02 & 28.00 & 2.89 \\
RP & 0.65 & 0.19 & 0.03 & 21.67 & 1.85 \\
RQ & 0.72 & 0.22 & 0.03 & 24.00 & 2.24 \\
PP & 0.66 & 0.25 & 0.04 & 16.50 & 2.37 \\
CM & 0.95 & 0.29 & 0.09 & 11.88 & 1.11 \\
A & 0.65 & 0.23 & 0.04 & 16.25 & 2.03 \\
SB & 0.90 & 0.37 & 0.08 & 11.25 & 1.90 \\
OC & 0.96 & 0.30 & 0.12 & 8.00 & 0.78 \\
SP & 0.58 & 0.25 & 0.09 & 6.44 & 1.08 \\
WG1 & 0.80 & 0.32 & 0.15 & 5.33 & 0.85 \\
WG2 & 0.95 & 0.55 & 0.20 & 4.75 & 1.59 \\
\hline
\end{tabular}

* Abbreviations of plant communities please refer to table 1 in detail

Specifically, slope wasteland and farmland possessed a relatively uniform soil texture, showing a small difference of content between coarse and fine soil particles. The curvatures of these two vegetation types fell between 0.78 and 1.90, indicating that their soil particles are poorly graded.

For economic and mixed forests, the uniformities ranged from 11.88 to 24 , and the curvatures varied between 1.11 and 2.37. Thus, these two vegetation types have well graded soil particles. For pure forest, the uniformity was $21.67 \sim 28$ and the curvature was 1.85 2.89, a signal of good grading.

\section{Discussion}

The soil texture can be evaluated by the contents and uniformities of soil particles in varied sizes. Being a porous medium, soil has a self-similar structure and certain fractal features. The fractal dimension is the main index of fractal features. Therefore, the relationship between uniformity and fractal dimension is conducive to the analysis on soil structure and texture. The relationship curves between the two factors were plotted 
(Figure 6) based on Tables 4 and 5, with fractal dimension as the $\mathrm{x}$-coordinate and uniformity as the y-coordinate.

The linear fitting results were $\mathrm{Y}=40.94 \mathrm{X}-79.325$ and $\mathrm{R}^{2}=0.7039$, indicating a significantly positive linear correlation between fractal dimension and uniformity, that is, the fractal dimension increases with uniformity. The complexity of soil texture depends on the quantitative distribution of soil particles in varied sizes (texture uniformity) and the soil aggregates (excluding small particles). It is found that the fractal dimension has a good linear correlation with the two feature parameters of soil texture, namely, the content of clay and powder particles and the uniformity. Hence, fractal dimension is a good index to quantify the soil structure and texture.

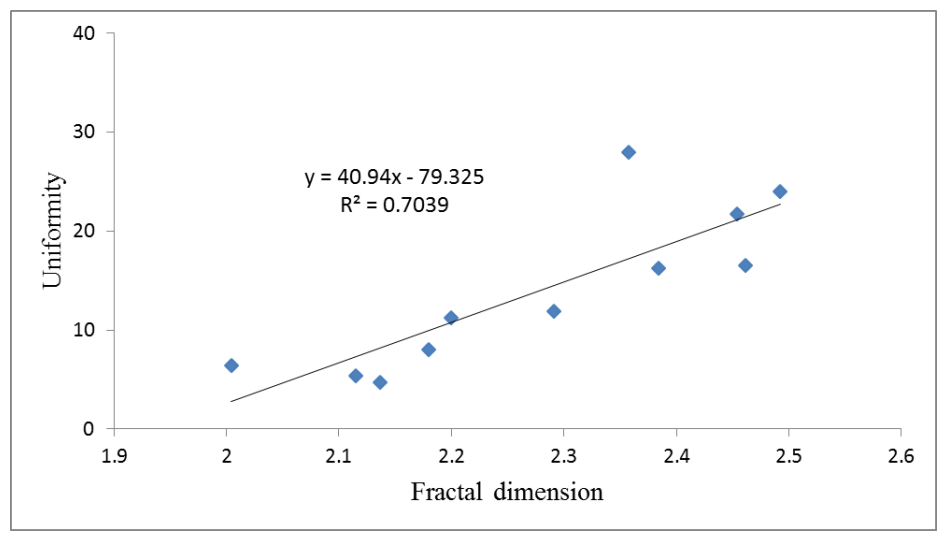

Figure 6. Correlation between fractal dimension and uniformity

In the aspect of soil fractal dimension used to quantitatively describe soil texture, physical properties and fertility characteristics, the existing studies show that when the soil texture changes from coarse to fine, the fractal dimension of soil particle composition changes from small to large (Yang et al., 1993; Zhao et al., 2016). The fractal dimension of soil with good texture structure and fertility is about $2.60 \sim 2.80$ (Zhao et al., 2016), while the soil fractal dimension of different plant communities in this study area is between 2.0044 and 2.4925 (average 2.2798, Fig. 4), which is smaller than the fractal dimension of well-structured soil and belongs to the range of sandy soil (1.834 2.641) (Lyu et al., 2015; Wei et al., 2016). Obviously, the higher the fractal dimension of soil, the stronger the function of improving soil structure.

The effect of the forest community on the soil physical structure is related to the nature of the fractal dimension of the soil particles, because the fractal dimension of the soil is used as the parameter to describe the soil structure geometry, and the filling capacity of the soil particle to the space is essentially reflected (Luo et al., 2015; Zhao et al., 2017). That is, the smaller the diameter of the soil particles, the higher the content of the finegrained material (the particles, the powder, the organic matter, etc.), the stronger the filling capacity of the space, the larger the fractal dimension of the soil, the better the formation of the better texture and the pore structure, and vice versa. This relationship is particularly evident in relatively coarse soil, such as sandy soil. It can also be said that in the mountainous area of coarse bone soil, forest community can increase the fractal dimension of soil by increasing the content of fine matter in soil, which is the fractal mechanism to improve the physical structure of soil and give full play to the function of soil and water conservation. 


\section{Conclusions}

The vegetation in fragile ecological areas easily degrades and the ecology is hard to preserve. This paper explores the effects of different plant communities on the physical properties of soil in the Yimeng Mountains of eastern China. Firstly, the composition, fractal features and size distribution indices (uniformity and continuity) of soil particles under 11 plant communities were discussed based on fractal theory. Next, the relationships between fractal dimension, particle size composition and uniformity were analyzed in details. The main conclusions were drawn as follows:

(1) The soil composition shows that the soil particle sizes ranged between 0.25 and $1.0 \mathrm{~mm}$ under different plant communities, indicating that the local soil is predominately coarse sandy soil. Both pure and mixed forests have high contents of clay and powder particles; the slope wasteland possesses high contents of fine sandy soils; the farmland witnesses a high content of sandy soils. The soil structure of forests is way better than that of slope wasteland, and the soil structure of mixed forest is markedly better than that of pure forest.

(2) The fractal dimensions of the 11 plant communities fell within a small interval: 2.0044 2.4925. RQ corresponded to the highest fractal dimension, followed by PP, RP, A, PT, CM, SB, OC, WG2, WG1 and SP in succession. The forests had higher dimensional values than the other vegetation types, revealing that forest species can greatly enhance soil structure. Among forest lands, mixed forest is the most effective vegetation type to ameliorate soil structure, followed by pure forest and economic forest.

(3) Fractal dimension has a linear correlation with the content of soil particles in each size. The linear correlation was significantly positive for fine sandy soil and coarse powder, as evidenced by $\mathrm{R}^{2}: 0.2888$ and 0.901 . By contrast, the linear correlation was significantly negative for coarse sandy soil, with the $\mathrm{R}^{2}$ being 0.7342 ; the linear correlation was not evident for gravel.

(4) PT led to the highest uniformity, followed in descending order by RQ, RP, PP, A, $\mathrm{CM}, \mathrm{SB}, \mathrm{OC}, \mathrm{SP}, \mathrm{WG} 1$ and WG2. By uniformity, the five vegetation types were ranked in ascending order as of slope wasteland $<$ farmland $<$ economic forest $<$ mixed forest $<$ pure forest. Thus, economic forest and mixed forest can significantly improve soil texture. Moreover, a positive linear correlation was observed between the uniformity and fractal dimension of each plant community $\left(\mathrm{R}^{2}=0.7039\right)$.

The above results shed new light on how to select tree species and design vegetation types to recover and reconstruct the vegetation in mountainous regions of eastern China, laying the technical basis for erosion control in fragile ecological areas. Further research will combine fractal analysis with the correlation analysis between fractal dimension and infiltration features in the study area.

Acknowledgements. This study was supported by the National Natural Science Foundation of China (No. 31500575) and a Project Funded by the Priority Academic Program Development of Jiangsu Higher Education Institutions (PAPD).

\section{REFERENCES}

[1] Deng, L. J., Lin, Z. Y., Gao, X. S., Zhang, S. R. (2008): Fractal feature of soil particles in the Chengdu plain. - Chinese Journal of Soil Science 39(1): 38-42. 
[2] Deng, J., Ma, C., Yu, H. (2018): Different soil particle-size classification systems for calculating volume fractal dimension-a case study of pinus sylvestris var. mongolica in mu us sandy land, China. - Appl Sci-Basel 8(10): 1872.

[3] Gao, G. L., Ding, G. D., Zhao, Y. Y., Wu, B., Zhang, Y. Q., Qin, S. G., Bao, T. F., Yu, M. H., Liu, Y. D. (2014): Fractal approach to estimating changes in soil properties following the establishment of Caragana Korshinskii, shelterbelts in Ningxia, NW China. - Ecol Indic 43: 236-243.

[4] Ghorbani, N., Raiesi, F., Ghorbani, S. (2012): Bulk soil and particle size-associated c and $\mathrm{n}$ under grazed and ungrazed regimes in mountainous arid and semi-arid rangelands. - Nutr Cycl Agroecosys 93(1): 15-34.

[5] Hu, Y. F., Liu, J. Y., Zhuang, D. F. (2003): Progress in Wind Erosion Research. - Progress in Geography 22(3): 288-295.

[6] Huang, C. Y. (2000): Soil Science. - 1st ed., China Agriculture Press: Beijing, China 7172.

[7] Jose, S. (2009): Agroforestry for ecosystem services and environmental benefits: an overview. - Agroforest Syst 76(1): 1-10.

[8] Li, X., Wei, X. (2014): Analysis of the relationship between soil erosion risk and surplus floodwater during flood season. - J Hydrol Eng 19(7): 1294-1311.

[9] Li, T., He, B., Zhang, Y., Tian, J. L., He, X. R., Yao, Y., Chen, X. Y. (2016): Fractal analysis of soil physical and chemical properties in five tree-cropping systems in Southwestern China. - Agroforest Syst 90(3): 457-468.

[10] Liu, X., Zhang, G. C., Heathman, G. C., Wang, Y. Q., Huang, C. H. (2009): Fractal features of soil particle-size distribution as affected by plant communities in the forested region of Mountain Yimeng, China. - Geoderma 154(1): 123-130.

[11] Luo, B. L., Chen, X. Y., Ding, L. Q., Huang, Y. H., Zhou, J., Yang, T. T. (2015): Response characteristics of soil fractal features to different land uses in typical purple soil watershed. - Plos One 10(4): e0122842: 1-19.

[12] Lyu, X., Yu, J., Zhou, M., Ma. B., Wang, G. M., Zhan, C., Han, G. X., Guan, B., Wu, H. F., Li, Y. Z., Wang, D. (2015): Changes of soil particle size distribution in tidal flats in the yellow river delta. - Plos One 10(3): e0121368: 1-12.

[13] Peng, G., Xiang, N., Lv, S. Q., Zhang, G. C. (2014): Fractal characterization of soil particlesize distribution under different land-use patterns in the yellow river delta wetland in China. - J Soil Sediment 14(6): 1116-1122.

[14] Perfect, E. (1997): Fractal models for the fragmentation of rocks and soils: a review. - Eng Geol 48(48): 185-198.

[15] Su, Y. Z., Zhao, H. L., Zhao, W. Z., Zhang, T. H. (2004): Fractal features of soil particle size distribution and the implication for indicating desertification. - Geoderma 122(1): 4349.

[16] Sun, J., Huang, C. H., Han, G., Wang, Y. (2019): Effects of cover on soil particle and associated soil nutrient redistribution on slopes under rainfall simulation. - J Soil Sediment 19(2): 729-740.

[17] Turcotte, D. L. (1986): Fractals and fragmentation. - J Geophys Res Solid Earth 91(B2): 1921-1926.

[18] Tyler, S. W., Wheatcraft, S. W. (1992): Fractal scaling of soil particle-size distributions: analysis and limitations. - Soil Sci Soc Am J 56(2): 362-369.

[19] Wei, X., Li, X., Wei, N. (2016): Fractal features of soil particle size distribution in layered sediments behind two check dams: implications for the Loess Plateau, China. Geomorphology 266: 133-145.

[20] Xia, D., Deng, Y. S., Wang, S. L., Ding, S. W., Cai, C. F. (2015): Fractal features of soil particle-size distribution of different weathering profiles of the collapsing gullies in the hilly granitic region, South China. - Nat Hazards 79(1): 455-478.

[21] Xiao, L., Xue, S., Liu, G. B., Zhang, C. (2014): Fractal features of soil profiles under different land use patterns on the loess plateau, China. - J Arid Land 6(5): 550-560. 
[22] Xu, G., Li, Z., Li, P. (2013): Fractal features of soil particle-size distribution and total soil nitrogen distribution in a typical watershed in the source area of the middle dan river, China. - Catena 101(2): 17-23.

[23] Yang, P. L., Luo, Y. P., Shi, Y. C. (1993): Fractal characteristics of soil by weight distribution of particle size. - Chinese Sci Bull 38(20): 1896-1899.

[24] Yu, J., Lv, X., Bin, M., Wu, H. F., Du, S. Y., Zhou, M., Yang, Y. M., Han, G. X. (2015): Fractal features of soil particle size distribution in newly formed wetlands in the yellow river delta. - Sci Rep-UK 5: 10540.

[25] Zhao, Q., Lu, X., Tang, Q., Zhang, W., Liu, P. (2016): Fractal dimension characteristic of soil particle size in the riparian buffer zone of the middle and lower reaches of the yellow river. - Science of Soil and Water Conservation 14(5): 37-45.

[26] Zhao, Y., Feng, Q., Yang, H. (2016): Soil salinity distribution and its relationship with soil particle size in the lower reaches of Heihe River, Northwestern China. - Environ Earth Sci 75(9): 1-18.

[27] Zhao, W. J., Cui, Z., Ma, H. (2017): Fractal features of soil particle-size distributions and their relationships with soil properties in gravel-mulched fields. - Arab J Geosci 10(9): 211. 